\title{
Numerical Simulation Research of the Influencing Factor of Vortex Tool Drainage Gas Recovery Technology
}

\author{
Chunsheng Wang, Bin Dong*, Yingfan Sun, Qiuying Du, Huijuan Chu and Jimin Yi
}

The Northeast Petroleum University, Daqing, Heilongjiang Province, 1633018, China

\begin{abstract}
The problem of effusion in gas well bottom hole grows increasingly serious in the late exploitation of gas field. The technology of vortex drainage has good prospects because the tool is conveniently manufactured and environmentally friendly. Currently, the mechanism for the vortex drainage and the theory of fluid motion are still missing. Therefore, in order to further realize the flow field of bottom hole, verify drainage mechanism and optimize working conditions, the study established a three-dimensional structural model of vortex tools to simulate the progress of gas well drainage by using the CFD software Fluent. By monitoring the liquid content of wellhead, liquid's radial distribution, and observing the flowing state of gas-liquid and the path line, it analyzes the influence of gas production rate, liquid producing capacity of wells and the main structure parameters of vortex tools (the length of the pitch of the helical blade and screw) on gas well flow field. The study revealed the working mechanism of vortex tools to facilitate the understanding of the nature of the vortex drainage process, guided the field how to select the preferred process conditions and provides the basis for optimizing the structure and provide theoretical basis for the application and the dynamic simulation of vortex drainage technology.
\end{abstract}

Keywords: Drainage, liquid loading, multiphase flow, numerical simulation, vortex tool.

\section{INTRODUCTION}

With the rapid development of the natural gas industry, one of the main problems in natural gas deep exploitation is the liquid loading of gas well. The direct cause of liquid loading of gas well is that gas reservoir contains water that constantly seeps into the wellbore. The ability of gas to carry liquids is insufficient and results in liquid loading. This has seriously influenced the effective exploitation of natural gas [1]. Choosing effective drainage gas recovery technology is the key to extend the gas well production cycle and enhance recovery [2].

Vortex drainage gas recovery technology is a new technology introduced by the China National Petroleum Corporation (the model as shown in Fig. (1)). The technology of vortex drainage has good prospects because the tool construction and construction work is simple, environmentally friendly and efficient [3]. However, due to the effect of vortex, tool drainage is influenced by gas reservoir properties, mining methods and production condition, sometimes it can hardly earn desired effect. Therefore, the application of vortex tools in the domestic oil field is still at the beginning of experimental testing in China. Sulige gas field carried out field trial for three seriously effusion gas wells ( $\mathrm{Su} 14-\mathrm{A}, \mathrm{Su}$ 14-B and $\mathrm{Su}$ 36-4-3) in 2011. The results of trial have shown that the maximum increases in daily gas production of single well is $542.1 \mathrm{~m}^{3} / \mathrm{d}$ and the minimum is $172.9 \mathrm{~m}^{3} / \mathrm{d}$, the effect of vortex tool is not apparent (detailed in Table 1) [4].

The mechanism for vortex drainage and the influence of production parameters to the drainage effect of this process

*Address correspondence to this author at the The Northeast Petroleum University, Daqing, Heilongjiang province, 1633018, China;

Tel: 15754591564; E-mail: 851955382@qq.com are still missing. Based on computational fluid dynamics, application of the fluent software on the use of vortex drainage gas recovery in gas wells simulation is calculated. Research down hole fluid flowing regularity verifies the effect of drainage gas, calculates the gas well production parameters and the spiral structure of the vortex tools on the influence of the gas drainage.

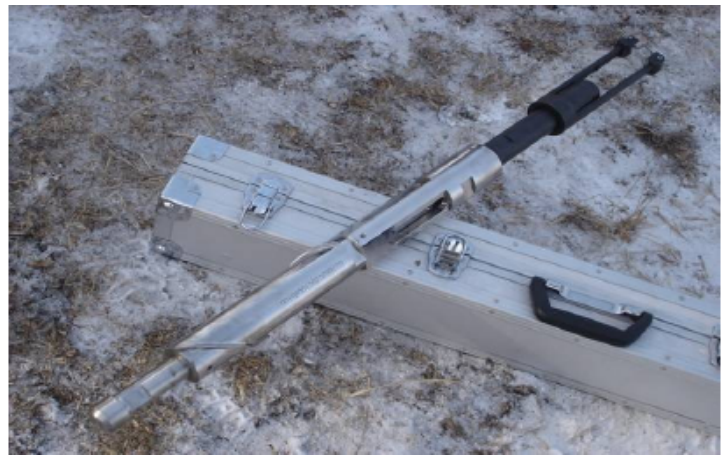

Fig. (1). The vortex tool.

Table 1. Results of field trial in Sulige gas field.

\begin{tabular}{|c|c|c|c|}
\hline \multirow{2}{*}{ Number } & \multirow{2}{*}{ Well number } & Before trial & After trial \\
\cline { 3 - 4 } & & $\begin{array}{c}\text { Daily gas } \\
\text { production }\left(\mathbf{m}^{3} / \mathbf{d}\right)\end{array}$ & $\begin{array}{c}\text { Daily gas } \\
\text { production }\left(\mathbf{m}^{3} / \mathbf{d}\right)\end{array}$ \\
\hline \hline 1 & $\mathrm{Su}$ 14-A & 4504.4 & 5046.5 \\
\hline 2 & $\mathrm{Su}$ 14-B & 7854.2 & 8126.7 \\
\hline 3 & $\mathrm{Su} \mathrm{36-4-3}$ & 6791.5 & 6964.4 \\
\hline
\end{tabular}




\section{BASIC THEORY OF GAS-LIQUID TWO PHASE MIXTURE MODEL}

This subject adopts the gas-liquid two-phase mixture model for numerical simulation, it is a simplified model of multiphase flow, and the volume fraction of the control body can be of any value range from 0 to 1 , allowing phases at different velocities. The control equation is as follows:

Continuity equation hybrid model:

$\frac{\partial}{\partial t}\left(\rho_{m}\right)+\frac{\partial}{\partial x_{i}}\left(\rho_{m} u_{m, i}\right)=0$

Momentum equation hybrid model:

$\frac{\partial}{\partial t}\left(\rho_{m} u_{m, j}\right)+\frac{\partial}{\partial x_{i}}\left(\rho_{m} u_{m, i} u_{m, j}\right)=-\frac{\partial p}{\partial x_{i}}+\frac{\partial}{\partial x_{i}} \mu_{m}$

$\left(\frac{\partial u_{m, i}}{\partial x_{j}}+\frac{\partial u_{m, j}}{\partial x_{i}}\right)+\rho_{m} g_{j}+F_{j}+\frac{\partial}{\partial x_{i}}\left(\sum_{k=1}^{n} \alpha_{k} \rho_{k} u_{D k, i} u_{D k, j}\right)$

The volume fraction of second phase $p$ equation:

$\frac{\partial}{\partial t}\left(\alpha_{p} \rho_{p}\right)+\frac{\partial}{\partial x_{i}}\left(\alpha_{p} \rho_{p} u_{m, i}\right)=-\frac{\partial}{\partial x_{i}}\left(\alpha_{p} \rho_{p} u_{p, i}\right)$

\section{MODEL}

\subsection{Structure and Principle}

The vortex tools consist of guide pins, helical blades, diversion channels, keyway and there are no moving parts in the tools. As shown in Fig. (2), the guide pin is located at the top of the tool and the keyway is located at the bottom of the tool. The tool is installed in the bottom hole through the connection of cable and guide pin and fixed within the oil tube through the keyway. The spiral blade is under the guide pin and the diversion tunnel is located under the spiral section. The down hole gas-liquid two-phase fluid enters into the spiral section through the diversion channel.

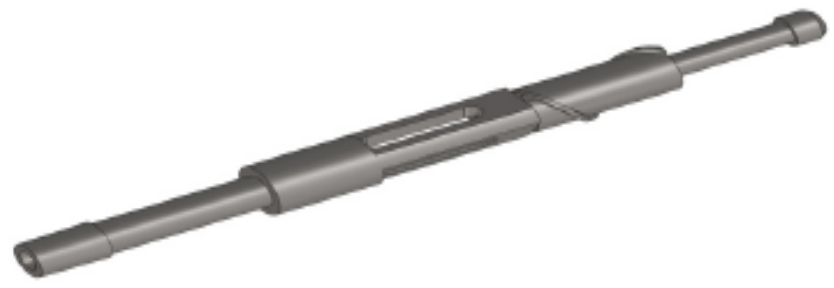

Fig. (2). The structure of vortex tool.

The principle of vortex drainage is: The down hole gasliquid mixing fluid enters into the helical annular space formed by the wellbore with the vortex tools, which makes fluid accelerate and rotate. Due to the effect of centrifugal force, most of the denser liquid fluid flows upward at high speed spirally along the well wall while the gas flows upward in the center of the wellbore, which effectively improves liquid density gradient distribution [5]. Irregular and inefficient gas-liquid mixing turbulent fluid is converted into the regular vortex fluid by vortex tools. Fluid is divided into the apparent gas-liquid two-phase stratified flow and flows along the wellbore upward for a long distance [6]. This kind of flowing pattern reduces the slippage loss and friction be- tween the mediums. It improves the gas flow rate and greatly improves the ability of gas to carry liquid [7]. The direct cause of liquid loading of gas well is that there is water in the gas pool, which constantly seeps into the wellbore. The rise of down hole back pressure increases the resistance of gas. Because the velocity is reduced and liquid carrying capacity is insufficient, more small droplets in the gas gather to merge back to the bottom hole [8].

\subsection{Grid}

The quality of grid is crucial for accurate numerical calculation. The structure of vortex tools is special and the computational domain is complex. Hence, not only the stability and precision of calculation, but also the calculation efficiency needs to be taken into account, which helps to get higher quality of grid. Based on the three-dimensional strong swirl characteristics of vortex tools, the meshing process is carried out so that the fluid area is divided into many sections thereby generating mesh. Wellbore part adopts cooper meshing method while helical annular space part adopts tetrahedral unstructured meshing method. In order to better capture the characteristics of flow boundary, the grid distribution is consistent with the calculation geometry and the domain geometry. Applying the non-uniform grid and reasonable arrangement of the grid pattern, we can not only guarantee grid quality of the swirling spiral annular cavity and other violent region to meet the computing requirements and ensure smooth calculation, but also control the total number of control grids in order to save computing time and resources. Fig. (3) is Examining Mesh process. The worst quality of grid is 0.6978 and meets the requirements of the vortex tool for numerical simulation.

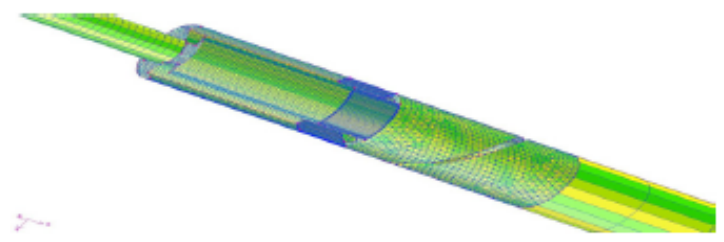

Fig. (3) .The mesh of vortex tool.

\section{NUMERICAL CALCULATION OF VORTEX DRAINAGE FLOW FIELD GAS WELL}

The simulation conditions of gas well are: the gas pressure is $10 \mathrm{Mpa}$, gas temperature is $85^{\circ} \mathrm{C}$, the oil pressure is $5 \mathrm{Mpa}$, the gas production rate is $104 \mathrm{~m}^{3} / \mathrm{d}$, and the liquid producing capacity is $2 \mathrm{~m}^{3} / \mathrm{d}$. The Fluent simulation adopts the mixture model of multiphase flow. Boundary condition is: the mass flow-rate inlet and pressure outlet. The wall boundary layers are dealt by the wall function to obtain the following results:

Through the flow field velocity Fig. (4), the vector diagram can be seen: the fluid motion state changes obviously in the well while passing the vortex tool and gas-liquid twophase fluid enters into the helical annular space which crosssectionally reduces suddenly through the diversion tunnel and then begins to accelerate and rotate along the direction of spiral vane.

Through the flow field path line Fig. (5), we can conclude that; The vortex tools make the high speed gas liquid two-phase mixed fluid rotate due to the stress. Fluid speed in 


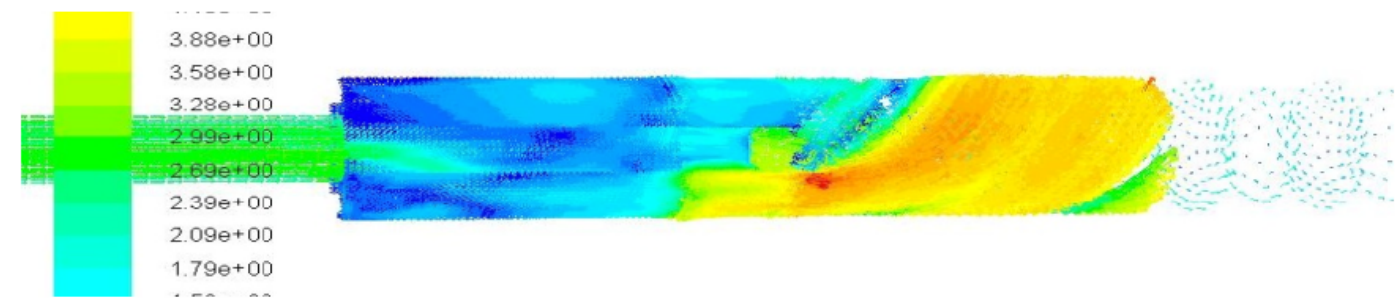

Fig. (4). The diagram of velocity vector in the flow field.

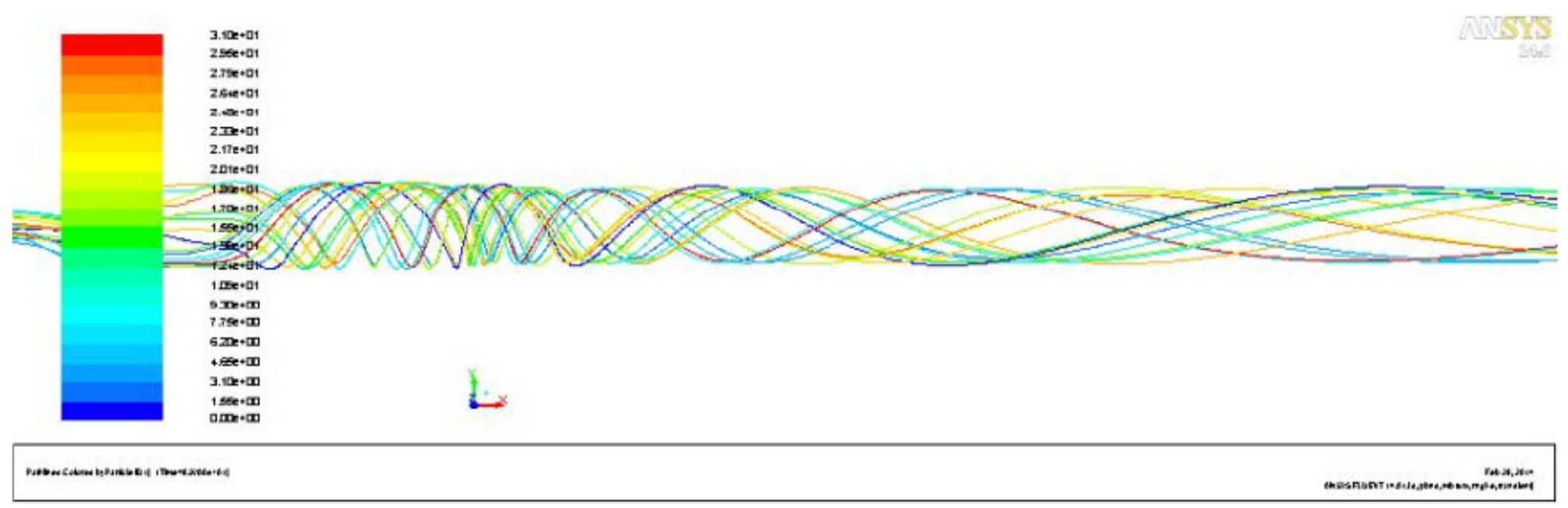

Fig. (5). The flow field path line.

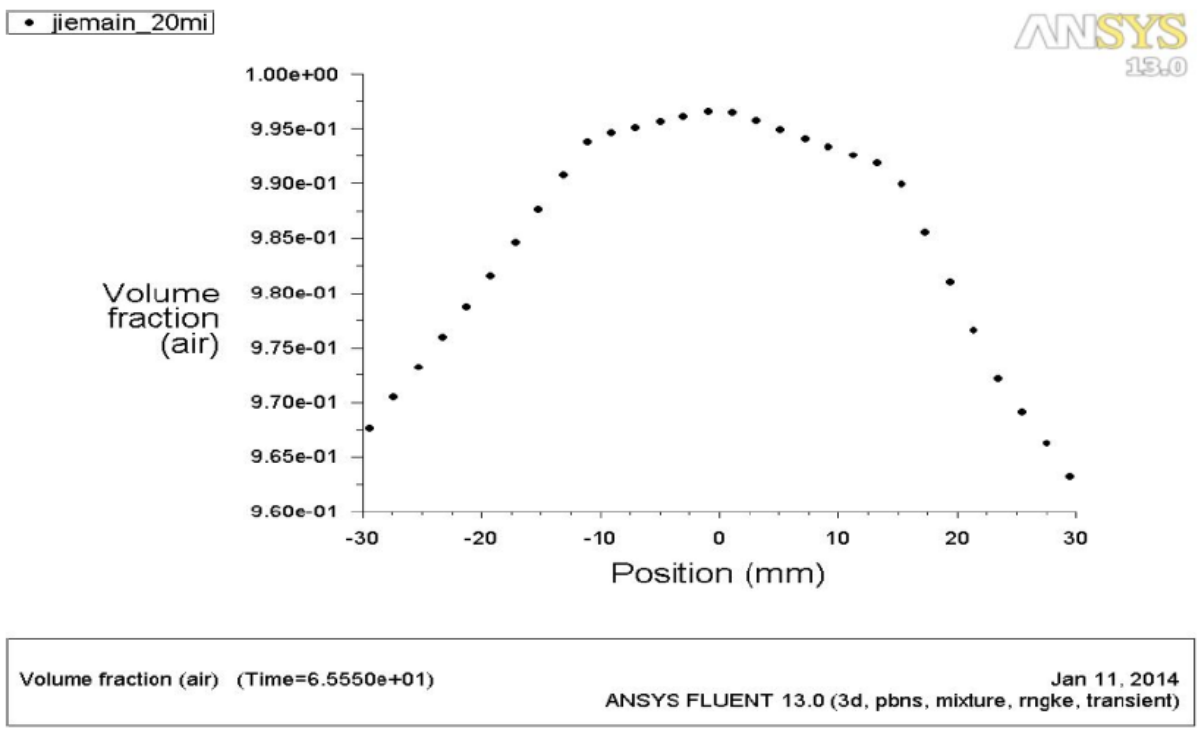

Fig. (6). Gas volume fraction distribution in wellhead section radial.

helical annular space has paths in line and flow state that change significantly. Fluid exhibits spiral upward movement when moving along the well wall.

Through the gas volume fraction distribution in wellhead section radial Fig. (6), it can be seen that gas well liquefies after passing the vortex tools, due to the effects of the centrifugal force which causes high speed rotation and most of the denser liquid is left in the wellbore periphery, with little remaining in the center of the well, while gas accumulates and travels upward to the center of the wellbore after the fluid passes the vortex tool. This effectively improves the density gradient distribution of the fluid. The fluid in the well changes into gas-liquid two-phase stratified spiral flow.

\section{THE INFLUENCES TO THE EFFECTS OF DRAIN- AGE BY THE PRODUCTION PARAMETERS OF GAS WELL}

Field experiments have found that the application of vortex drainage technology for gas wells of different production parameters has different effects. This study calculates the gas wells of different gas production rates and water content of bottom hole, comparing gas wells which use vortex drainage with normal ones.

(1) The gas production rate of wells directly affects the ability of carrying liquid. Remaining liquid flow rate of the bottom of a well remain unchanged as $2 \mathrm{~m}^{3} / \mathrm{d}$, the study separately calculated the quantity of liquid in wellhead of the wells which used vortex tool and ordinary gas well when gas 
production rates were $2500 \mathrm{~m}^{3} / \mathrm{d}, 5000 \mathrm{~m}^{3} / \mathrm{d}, 10000 \mathrm{~m}^{3} / \mathrm{d}$, $15000 \mathrm{~m}^{3} / \mathrm{d}$ and $20000 \mathrm{~m}^{3} / \mathrm{d}$. We recorded the monitoring vortex tools well and not application of vortex drainage gas recovery in the wellhead liquid integral and calculated the vortex drainage process which increased the percentage of drainage as shown in Table $\mathbf{2}$.

Table 2. Vortex drainage gas recovery and general well with fluid contrast table.

\begin{tabular}{|c|c|c|c|}
\hline \multirow{2}{*}{$\begin{array}{c}\text { Daily Gas } \\
\text { Production } \\
\left(10^{4} \mathrm{~m} / \mathrm{d}\right)\end{array}$} & \multicolumn{2}{|c|}{$\begin{array}{c}\text { The Volume Fraction of the } \\
\text { Liquid Wellhead (\%) }\end{array}$} & \multirow{2}{*}{$\begin{array}{l}\text { Vortex Tools } \\
\text { Increase the } \\
\text { Percentage of } \\
\text { Drainage (\%) }\end{array}$} \\
\hline & $\begin{array}{l}\text { Ordinary } \\
\text { Well }\end{array}$ & $\begin{array}{c}\text { Vortex Drain } \\
\text { Well }\end{array}$ & \\
\hline 0.25 & 10.043 & 10.107 & 0.638 \\
\hline 0.5 & 3.899 & 4.155 & 6.561 \\
\hline 1 & 1.708 & 1.901 & 11.332 \\
\hline 1.5 & 1.5 & 1.139 & 10.259 \\
\hline 2 & 0.800 & 0.877 & 9.585 \\
\hline
\end{tabular}

Daily gas production of gas wells directly reflects the gas flow rate; the water of the gas wells is in gas medium transport, simulation calculation of the speed of the fluid carried in the gas well is necessary. Therefore, we monitored the volume fraction of the export gas carrying liquid and obtained the following results.

Through the calculation results in Table 2, Fig. (7) and Fig. (8), we can conclude: the volume fraction of the liquid wellhead of ordinary well and vortex drain well reduce while daily gas production raises (daily gas production increases from $2500 \mathrm{~m}^{3} / \mathrm{d}$ to $20000 \mathrm{~m}^{3} / \mathrm{d}$ while the volume fraction of the liquid wellhead of ordinary well decreases from $10.043 \%$ decreased to $0.8 \%$ and the vortex drain well decreases from $10.107 \%$ to $0.877 \%$ ); the vortex tools increase the percentage of drainage with the increase in daily gas production while daily gas production is less than $10^{4} \mathrm{~m} / \mathrm{d}$ (daily gas production increases from $2500 \mathrm{~m}^{3} / \mathrm{d}$ to $10000 \mathrm{~m}^{3} / \mathrm{d}$ and percentage of drainage increases from $0.638 \%$ to $11.332 \%$ ), when daily gas production is more than $10^{4} \mathrm{~m}^{3} / \mathrm{d}$, vortex tools increase the percentage of drainage decreases slightly(daily gas production increases from $10^{4} \mathrm{~m}^{3} / \mathrm{d}$ to $2 \times 10^{4} \mathrm{~m}^{3} / \mathrm{d}$ and percentage of drainage decreases from $11.332 \%$ to $9.585 \%$ ). The maximum percentage of drainage is $11.332 \%$ while daily gas production is $10^{4} \mathrm{~m} / \mathrm{d}$. The vortex drainage technology can obviously improve the gas well's ability to carry liquid and the gas production rate of wells directly affecting the ability of carrying liquid.

(2) The liquid producing capacity of wells also has an important effect on vortex tools drainage. Gas production rate of the well remained unchanged as $5000 \mathrm{~m}^{3} / \mathrm{d}$, the study separately calculated the quantity of liquid in wellhead of the wells which used vortex tool and ordinary gas wells when liquid producing capacity were $1 \mathrm{~m}^{3} / \mathrm{d}, 2 \mathrm{~m}^{3} / \mathrm{d}, 3 \mathrm{~m}^{3} / \mathrm{d}, 4 \mathrm{~m}^{3} / \mathrm{d}$ and $5 \mathrm{~m}^{3} / \mathrm{d}$.

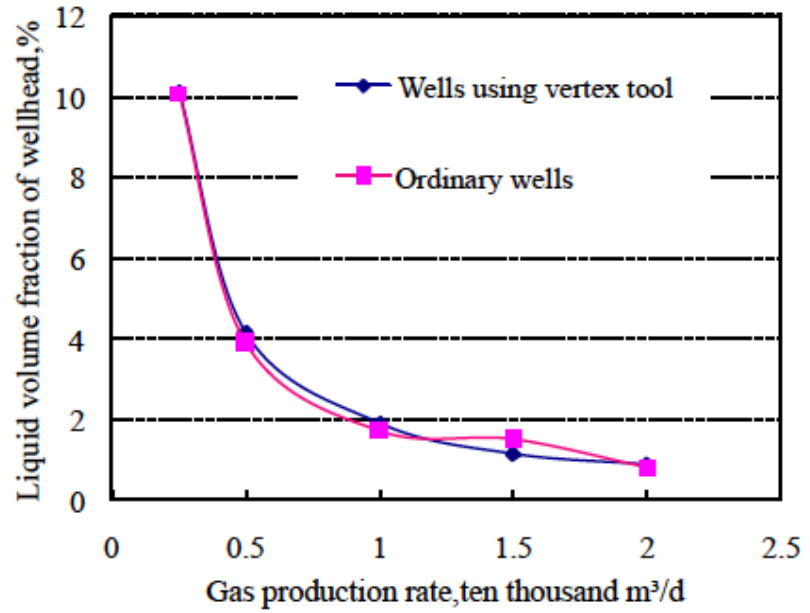

Fig. (7). Relation curves between liquid volume fraction of wellhead and gas production rate per day.

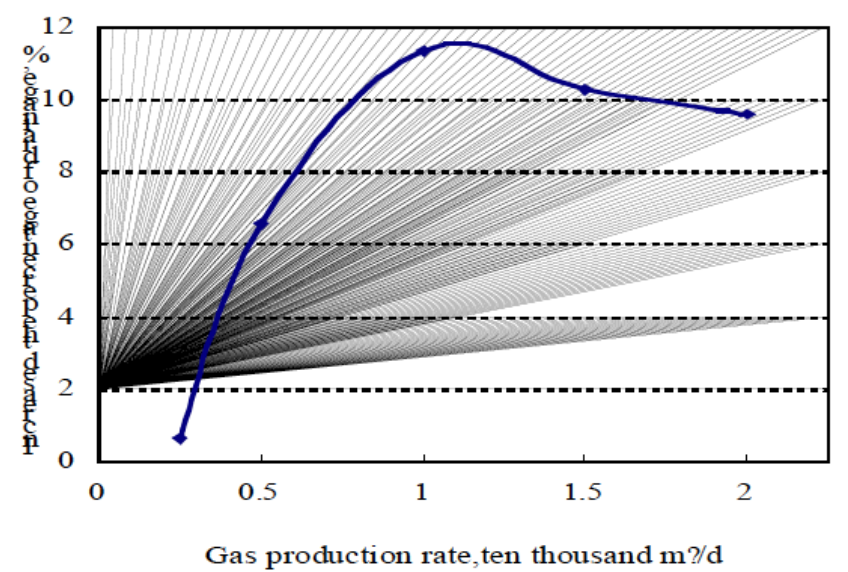

Fig. (8). Relation curves between increased percentage of drainage and gas production rate per day.

The simulation calculation used vortex tools well and ordinary well to compare and analyze under the same conditions which attained the following date curve:

Through the calculation results shown in Table $\mathbf{3}$ and Fig. (9) and Fig. (10), it can be concluded that the liquid producing capacity of wells affects the ability of carrying liquid significantly, when the liquid producing capacity of wells is under $4 \mathrm{~m}^{3} / \mathrm{d}$, the drainage increases (ordinary well increases from $2.0111 \%$ to $7.358279 \%$ and vortex drain well increases from $2.01328 \%$ to $8.56939 \%$ ). When the liquid producing capacity of wells is higher than $4 \mathrm{~m}^{3} / \mathrm{d}$, the produced liquid quantity of wellhead grows slowly or even declines (ordinary well decreases from $7.358279 \%$ to $6.65141 \%$ and vortex drain well increases slightly from $8.56939 \%$ to $9.479031 \%$ ). The water in the well cannot be completely bled off from the wellhead resulting effusion. At this time, using vortex tools can significantly improve the effect of drainage, the vortex tools increase the percentage of drainage with the increase in daily liquid production apparently (daily liquid production increased from $1 \mathrm{~m}^{3} / \mathrm{d}$ to $5 \mathrm{~m}^{3} / \mathrm{d}$ and percentage of drainage from $0.1084 \%$ increased to $42.552 \%$ ) and the more the liquid producing capacity is, the bigger the growth rate of drainage of wells. 
Table 3. Liquid producing capacity has different effect on drainage.

\begin{tabular}{|c|c|c|c|}
\hline \multirow{2}{*}{$\begin{array}{c}\text { Liquid } \\
\text { Producing } \\
\text { Capacity } \\
\left(\mathrm{m}^{3} / \mathrm{d}\right)\end{array}$} & \multicolumn{2}{|c|}{$\begin{array}{l}\text { The Volume Fraction of the } \\
\text { Liquid Wellhead (\%) }\end{array}$} & \multirow{2}{*}{$\begin{array}{l}\text { Vortex Tools } \\
\text { Increase the } \\
\text { Percentage of } \\
\text { Drainage (\%) }\end{array}$} \\
\hline & $\begin{array}{l}\text { Ordinary } \\
\text { Well }\end{array}$ & $\begin{array}{c}\text { Vortex Drain } \\
\text { Well }\end{array}$ & \\
\hline 1 & 2.0111 & 2.01328 & 0.1084 \\
\hline 2 & 4.0427 & 4.1545 & 2.765 \\
\hline 3 & 6.3214 & 6.6786 & 5.65 \\
\hline 4 & 7.358279 & 8.56939 & 16.459 \\
\hline 5 & 6.65141 & 9.479031 & 42.552 \\
\hline
\end{tabular}

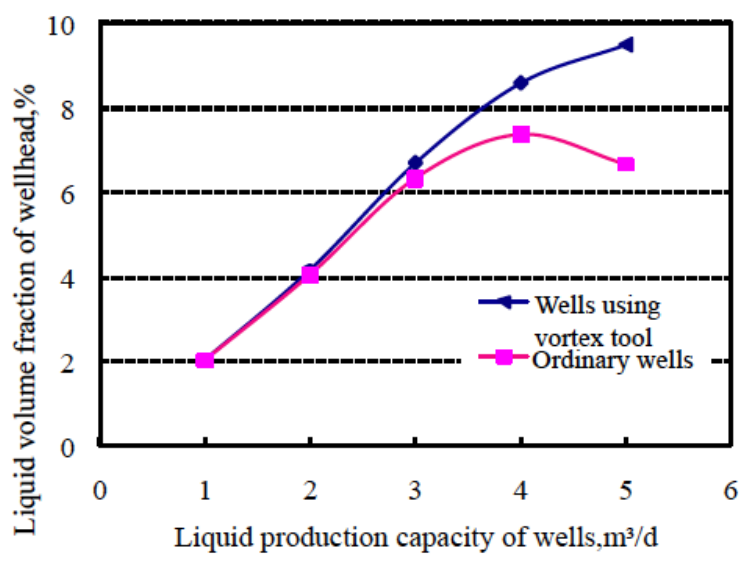

Fig. (9). Relation curves between liquid volume fraction of wellhead and liquid producing capacity.

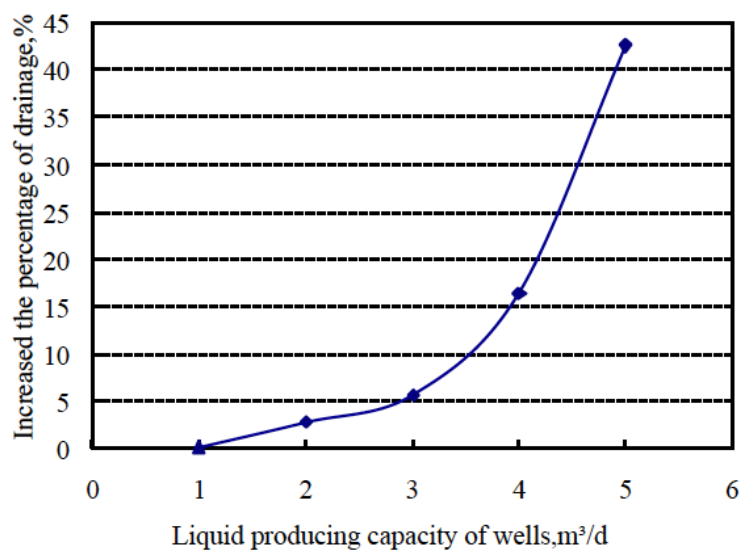

Fig. (10). Relation curves between increased percentage of drainage and liquid producing capacity.

\section{THE INFLUENCE ON THE EFFECT OF DRAIN- AGE BY HELICAL STRUCTURE PARAMETERS OF VORTEX TOOLS}

The gas well production parameters have important effects on vortex drainage process, besides, the vortex tools with different structures will also result in different drainage effects. The main structure factors that influence the effects of vortex drainage are spiral blade pitch and screw length.
Helical structure parameters or the diversion channel transform will change the state of fluid motion.

As shown in Fig. (11), changing spiral structure parameters on the basis of the original vortex tool model, we respectively established nine vortex tool models whose spiral length were $127 \mathrm{~mm}, 254 \mathrm{~mm}, 381 \mathrm{~mm}$ and thread pitch were $127 \mathrm{~mm}, 63.5 \mathrm{~mm}$ and $42.33 \mathrm{~mm}$. And the quantity of well fluid was calculated under the same condition (bubble diameter was $0.07 \mathrm{~mm}$ ) gas production rate was $10000 \mathrm{~m}^{3} / \mathrm{d}$ and the liquid producing capacity was $2 \mathrm{~m}^{3} / \mathrm{d}$ ).
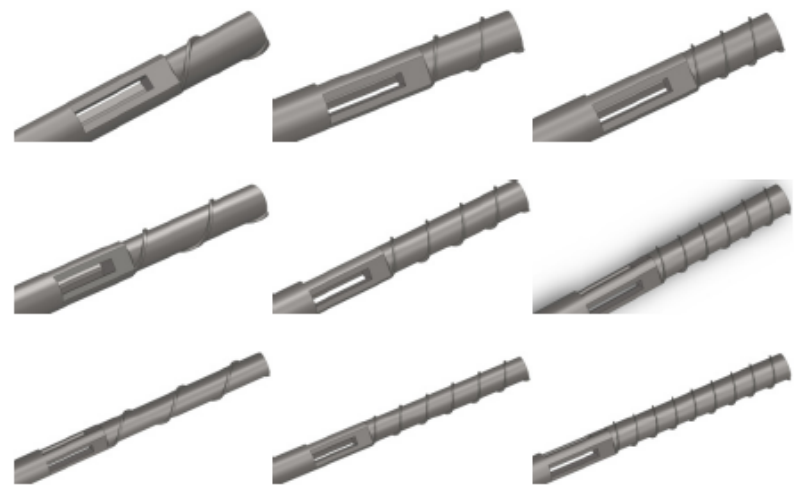

Fig. (11). Vortex tool $3 d$ model of different helical structure parameters.

As an example, spiral length was $254 \mathrm{~mm}$, the pitch was $127 \mathrm{~mm}, 63.5 \mathrm{~mm}$ and $42.33 \mathrm{~mm}$, respectively. Following Fig. (12) to Fig. (14) is flow velocity vector diagram of pitch $127 \mathrm{~mm}, 63.5 \mathrm{~mm}, 42.33 \mathrm{~mm}$.

We record and analyze the nine different structural parameters of eddy current tools of well-site characteristics and the volume fraction of the liquid wellhead, summarizing the results and drawing as shown in the following relation curves.

Through the results of different structural parameters of vortex tool models shown in the Table 4 and Fig. (15), we can conclude: fixed screw length and decreased pitch of thread can improve the quantity of liquid on the wellhead, for instance, when spiral length is $127 \mathrm{~mm}$, volume fraction of the liquid wellhead decreases from $1.97909 \%$ to $1.904 \%$ while pitch increases from $42.33 \mathrm{~mm}$ to $127 \mathrm{~mm}$; fixed pitch and increased spiral length also improve the quantity of liquid on the wellhead, for instance, when pitch is $42.33 \mathrm{~mm}$, volume fraction of the liquid wellhead increases from $1.97909 \%$ to $2.1 \%$ while pitch increases from $127 \mathrm{~mm}$ to $381 \mathrm{~mm}$. Otherwise, while the length of helical pitch is less than $60 \mathrm{~mm}$, it may have significant effect of drainage.

However, the vortex tools offer resistance of the fluid in the gas well, and fluid flow through the vortex tools overcomes the resistance to work. Therefore, it is necessary to calculate and analyze the drop of fluid's pressure in gas well caused by vortex tools of different structures.

By simulating different structures of vortex tools influence of the pressure drop in gas, through the results shown in Table 5 and Fig. (16), we can obtain the following conclusions: it is not that the longer the spiral section and the smaller the pitch, the better it is for gas well production. When the screw length remains constant, the shorter the 


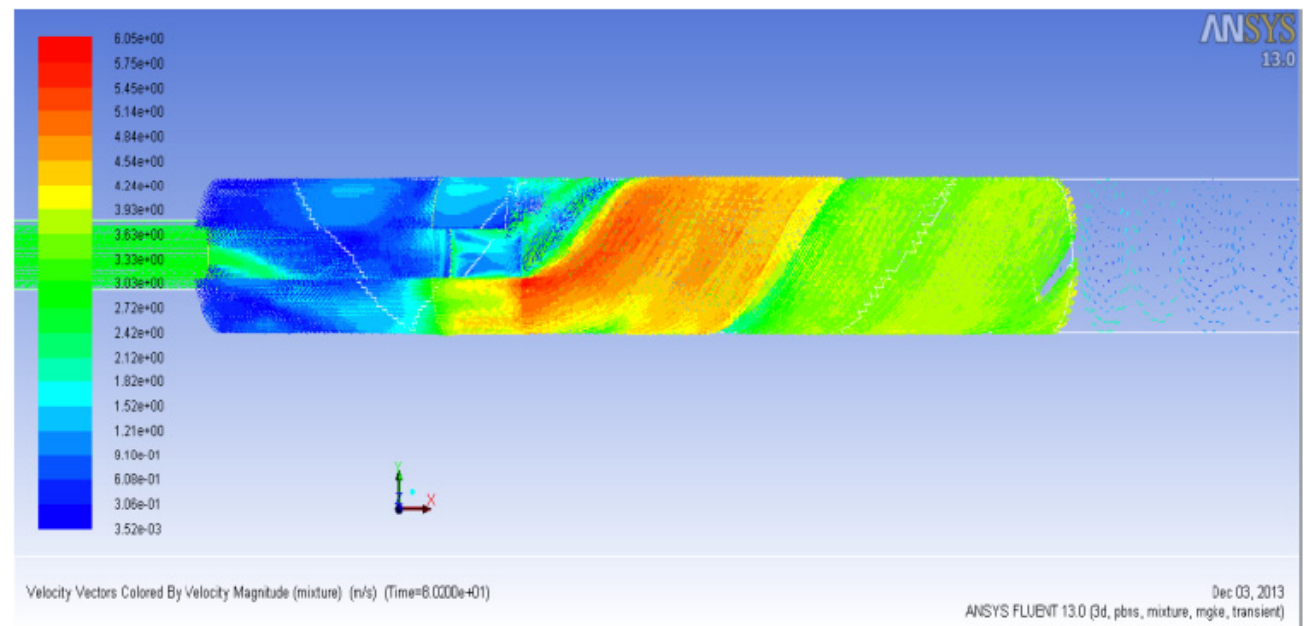

Fig. (12). Pitch $127 \mathrm{~mm}$.

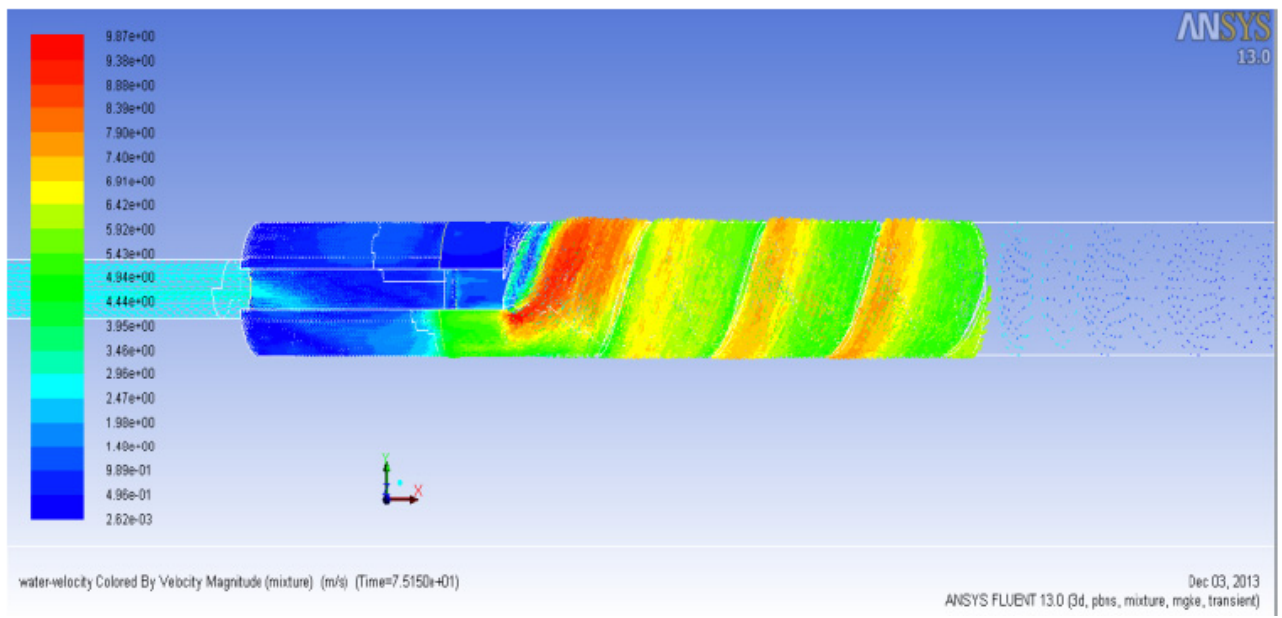

Fig. (13). Pitch $63.5 \mathrm{~mm}$.

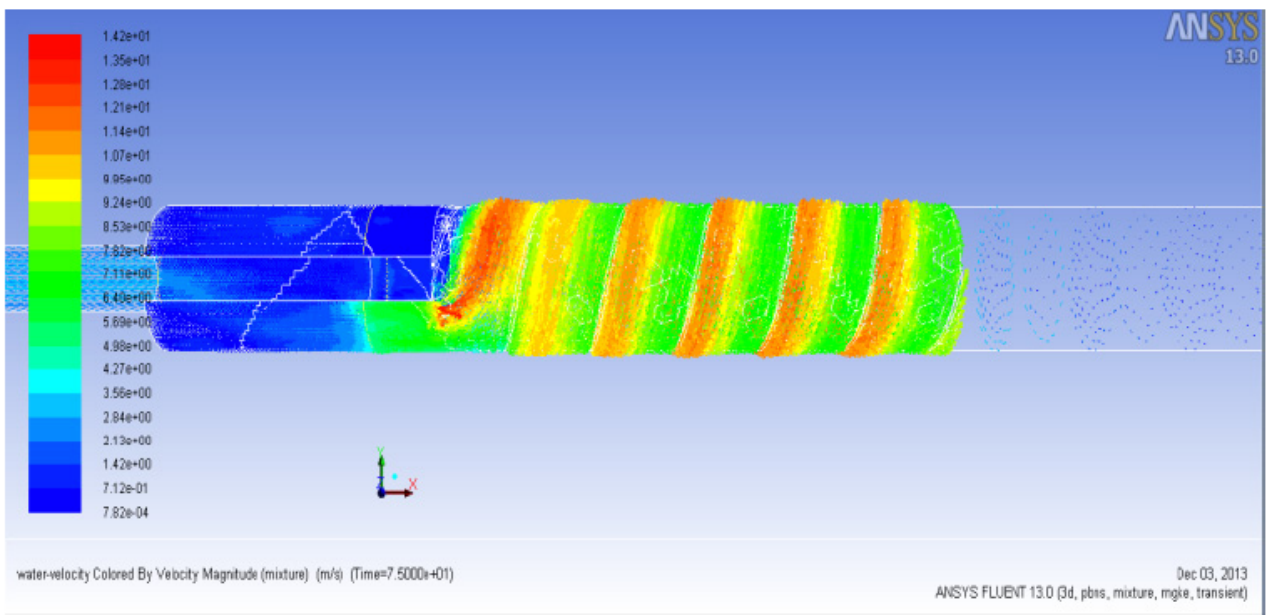

Fig. (14). Pitch $42.33 \mathrm{~mm}$.

pitch is, the greater the pressures drop, for instance, when spiral length is $127 \mathrm{~mm}$, the pressure loss decreases from $13415 \mathrm{~Pa}$ to $2127 \mathrm{~Pa}$ while pitch increases from $42.33 \mathrm{~mm}$ to $127 \mathrm{~mm}$; when the pitch is less than $60 \mathrm{~mm}$, increasing the screw length will increase the pressure loss, the smaller the helical pitch the more the coil numbers and the pressure loss will be bigger, for instance, when pitch is $42.33 \mathrm{~mm}$, the pressure loss increases from $13415 \mathrm{~Pa}$ to $33239 \mathrm{~Pa}$ while spiral length increases from $127 \mathrm{~mm}$ to $381 \mathrm{~mm}$. With Spiral length $381 \mathrm{~mm}, 42.33 \mathrm{~mm}$ pitch, and the spiral number 9 times, then pressure decreased to $3.3 \mathrm{Mpa}$. Therefore the helical structure cannot be blindly increased. 
Table 4. Helical structure parameters has different effect on drainage.

\begin{tabular}{|c|c|c|c|}
\hline \multirow{2}{*}{ Pitch (mm) } & \multicolumn{3}{|c|}{ The Volume Fraction of the Liquid Wellhead (\%) } \\
\cline { 2 - 4 } & $\begin{array}{c}\text { Spiral Length } \\
\text { (127 mm) }\end{array}$ & $\begin{array}{c}\text { Spiral Length } \\
\text { (254mm) }\end{array}$ & $\begin{array}{c}\text { Spiral Length } \\
\text { (381 mm) }\end{array}$ \\
\hline \hline 42.33 & 1.97909 & 2.03227 & 2.1 \\
\hline 63.5 & 1.9398 & 1.93059 & 1.94818 \\
\hline 127 & 1.904 & 1.8841 & 1.906 \\
\hline
\end{tabular}

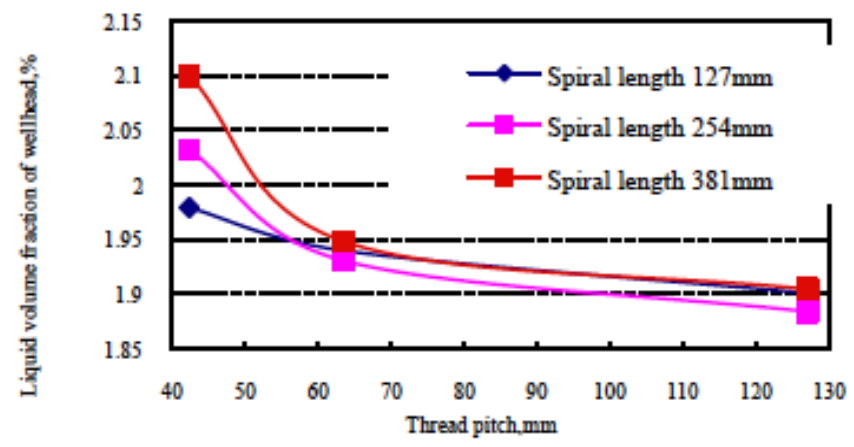

Fig. (15). Relation curves between volume fraction of liquid and the structure of vortex tool.

Table 5. Different structures vortex tools cause fluid pressure gas loss.

\begin{tabular}{|c|c|c|c|}
\hline \multirow{2}{*}{ Pitch (mm) } & \multicolumn{3}{|c|}{ The Fluid Pressure Loss (Pa) } \\
\cline { 2 - 4 } & $\begin{array}{c}\text { Spiral Length } \\
(\mathbf{1 2 7} \mathbf{m m})\end{array}$ & $\begin{array}{c}\text { Spiral Length } \\
\mathbf{( 2 5 4 m m )}\end{array}$ & $\begin{array}{c}\text { Spiral Length } \\
\text { (381 mm) }\end{array}$ \\
\hline \hline 42.33 & 13415 & 21667 & 33239 \\
\hline 63.5 & 5719.8 & 8296.2 & 10788 \\
\hline 127 & 2127 & 2379 & 2863 \\
\hline
\end{tabular}

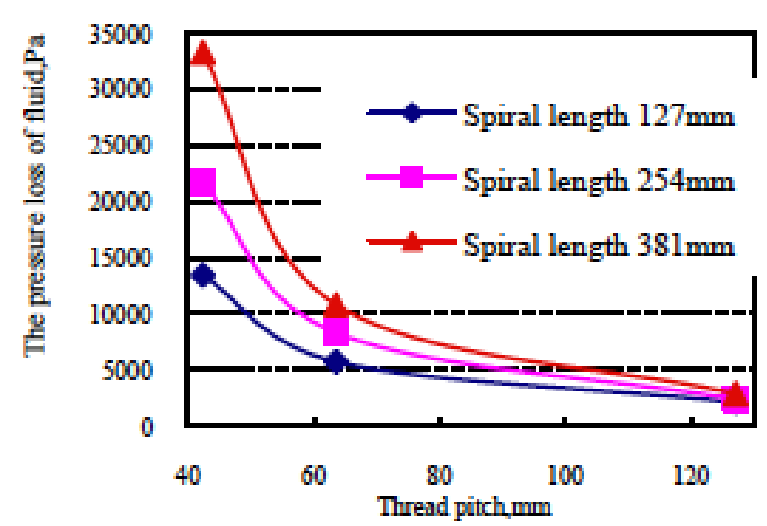

Fig. (16). Relation curves between pressure loss and the structure of vortex tool.

\section{CONCLUSION AND SUGGESTION}

Considering the application of the vortex tools in the drainage process, various researches were done for the vor- tex tool through computational fluid dynamics method in this paper. Meshing quality of gas well fluid of domain and simulation for the movement of fluid in the gas well is calculated by Fluent, in-depth analysis of flow pattern, we calculated and analyzed the production parameters of the gas well and helical structure of vortex tools which influenced on water-bearing gas well drainage, and obtained the following conclusions:

(1) Vortex tools can change gas well fluid motions, fluid is accelerated by the role of vortex tools and along the direction of spiral vane and the wellbore rotating flow upward at high speed, the gas phase concentrate in the center of the wellbore, the liquid phase is dumped near the wellbore wall, the borehole fluid changes into gas-liquid two-phase stratified flow obviously.

(2) The gas well production has critical impact on the ability of carrying liquid. The larger the gas production capacity, the faster it can carry liquid. Vortex tools have an optimum gas production improving the drainage gas recovery effect. Improving the quantity of drainage the best gas production is $10^{4} \mathrm{~m}^{3} / \mathrm{d}$ to $2.25 \times 10^{4} \mathrm{~m}^{3} / \mathrm{d}$ by simulating. The gas production is too low, so it will affect the ability of carrying liquid and it is not conducive to the production. When gas production exceeds to a certain value, the gas of the well can complete drainage without vortex tools

(3) The liquid producing capacity of wells has profound influence on the ability of carrying liquid. As to particular structure of the vortex tools, there is usually an appropriate daily gas production, which enables the vortex tools to play the best role in the field.

It was observed through computer simulation that the daily gas production is $5000 \mathrm{~m}^{3}$ and the liquid producing capacity of wells above $3 \mathrm{~m}^{3} / \mathrm{d}$ will produce effusion. Using vortex tools can improve the effect of drainage significantly.

(4) Through the different structural parameters of eddy current tools' simulation, the results show that increasing the length of the spiral can increase the amount of gas drainage in the case of small pitch. But adding laps will lead to more pressure drop in gas. Structural optimization should be based on the actual well conditions, rather than increasing the helical structure blindly.

\section{LIST OF SYMBOLS}

$$
\begin{aligned}
\alpha_{\mathrm{k}} & =\text { k-phase volume fraction } \\
\mathrm{n} & =\text { Number of phases } \\
\rho_{\mathrm{m}} & =\text { Mixture density, } \mathrm{kg} / \mathrm{m}^{3} \\
\vec{u}_{D k} & =\text { k-phase drift velocity, } \vec{u}_{D k}=\vec{u}_{k}-\vec{u}_{m}, \mathrm{~m} / \mathrm{s} \\
\mu_{m} & =\text { Mixed viscosity, Pa.s } 0 \\
\vec{u}_{m} & =\text { Mass average velocity, } \mathrm{m} / \mathrm{s}
\end{aligned}
$$

\section{CONFLICT OF INTEREST}

The authors confirm that this article content has no conflict of interest. 


\section{ACKNOWLEDGEMENTS}

The authors would like to thank Mrs. Feng for her support in theoretical basis, directing numerical simulation and analyzing problems.

\section{REFERENCES}

[1] S. L. Li, "Natural Gas Engineering”, Beijing: Petroleum Industry Press, 2009.

[2] C. J. Feng, C. S. Wang, and H. Zhang, "Influencing factor analysis of the liquid discharge effect of down hole vortex tool in natural gas wells", Journal of Petroleum Machinery, vol. 41, no. 1, pp. 7881, 2013.

[3] H. T. Le, R. Jian, and Y. Y. Ge, The Drainage Gas Recovery Technology. Beijing: Petroleum Industry Press, 2011.
[4] Q. Yue, X. J. Zhang, N. N. Zhou, J. Zhou, Z. T. Wei. "Analysis of the effect of vortex tool field trial in Su14 block", Ningxia Young Scientists Forum Petrochemical Forums, vol. 11, no. 3, pp. 335337, 2012.

[5] G. R. Mingaleeva, "On the mechanism of a helical motion of fluids in regions of sharp path bending", Technical Physics Letters, vol. 28, no. 8, pp. 657-659, 2002 .

[6] A. J. Ali, S. L. Scott and B. Fehn, "Investigation of new tool to unload liquids from stripper-gas wells", SPE Production \& Facilities, vol. 20, no. 4, pp. 306-316, 2005.

[7] T. Yang, S. Yu, H. Yang, J. Li, N. Li, G. Cao, and Y. Wang, "A new technology of vortex dewatering gas recovery in gas wells and its application", Journal of Natural Gas Industry, vol. 32, no. 8, pp. 63-66, 2012.

[8] Z. C. Jin, C. D. Yang, and S. L. Zhang, "Gas Recovery Engineering”, Beijing: Petroleum Industry Press, 2004.

(C) Wang et al.; Licensee Bentham Open.

This is an open access article licensed under the terms of the Creative Commons Attribution Non-Commercial License (http://creativecommons.org/licenses/by-nc/3.0/) which permits unrestricted, non-commercial use, distribution and reproduction in any medium, provided the work is properly cited. 